\title{
Human resources accounting and accountability: medical aspects, regulation and economics of burn out in non-financial reporting
}

\author{
Razvan HOINARU \\ Queen Mary University of London, London, UK \\ r.hoinaru@qmul.ac.uk \\ Adin Daniel ROBE \\ Attending Psychiatrist at PC Glostrup, Copenhagen, Denmark \\ adin.daniel.robe@gmail.com \\ Andreia MANEA (STANCIU) \\ Bucharest University of Economic Studies, Bucharest, Romania \\ maneaandreia14@stud.ase.ro \\ Costin DAMASARU \\ Neuro Performance Enhancement Center, Bucharest, Romania \\ Office@npecenter.com \\ Sorin NIŢ $\breve{A}$ \\ Bucharest University of Economic Studies, Bucharest, România \\ cristians.nita@fabiz.ase.ro
}

\begin{abstract}
The economics of burnout is estimated at around $\$ 300$ bn globally, reaching a point where the World Health Organisation could declare a pandemic in the foreseeable future. There are obviously financial losses due to burnout, however, there are also financial gains for the pharma industry and therapists. In this article we shall put some data in balance, but also look at deeper regulatory implications, for companies, hospitals and people. Along with exploring causes and financial impacts, we shall look at how non-financial reporting can provide more timely guidance and alarm signals, better social responsibility disclosure practices where medical reports are more material, not just a set of issues. The time is right to revisit the Human Resource Accounting (HRA) practice from both its traditional cost approach perspective and also from present challenges to understand how value is put at risk.
\end{abstract}

Key words: burn-out, non-financial reporting, economic value, accountability

\section{Introduction}

This article has a cross-disciplinary approach towards burn out treatment in non-financial reporting and represents the efforts of five academics and practitioners with different backgrounds: accounting, finance, medical (psychiatry), psychology and regulatory. Originally, each scholar wrote their own part and while redrafting all parts were made to react to one another. The time is right for such an article for two reasons: the World Health Organisation pulled the alarm signal on burnout issues, its costs to the economy and the fact that the world is at risk for a pandemic of burn out. Secondly, because non-financial reporting practices are under revision, and informing policymakers and preparers, may lead to binding aspects of this subject matter. In this sense, even organisations like EFRAG mandated to produce advice on financial disclosures endorsements to 
the European Commission and European Parliament produces work on sustainability in financial and non-financial reporting (EFRAG, 2021).

The main idea of this article is to provide input to the process of developing non-financial reporting standards as well as driving attention to burn out as a syndrome, not yet a disease. The authors of this article do not consider burn out from the perspective of company culture, considering 'toxic' working environments, but rather how the financial value of a company if data in this sense would be appropriately disclosed. Random non-financial reports will be analysed, to check on data on human resources disclosures, specifically looking for burn out Our work is structured as follows: the first part considers burn out from a medical technical perspective, presenting definitions, causes and medication for such a medical disorder. The second part looks at the academic literature on burnout from a non-medical professional perspective and to some extent, country by country. Burn out affects all the professions in all industries at an alarming rate of $69 \%$ on average, with certain places like Australia, putting forward a better perspective. The third part specifically looks at the existing and potential future technical correlations in between burnout and non-financial reporting. The challenge to connect the two relates to the fact that Directive 2014/95/EU is rather weak, while the rest of reporting standards and frameworks are not harmonised and do not necessarily address all the same issues. Our research concludes that better decision usefulness should be present in NFI, burnout should be considered outside its medical considerations, in view of materiality in the public interest.

\section{Burn out from a medical perspective}

The main diagnostics manual used in Europe is ICD-11. Burnout syndrome is caused by enduring chronic stress at the place of work, which the afflicted person does not have a coping mechanism for. It is usually described by the client or patient as having a lack of energy or feeling exhausted, becoming more distant in relation to the work or to the work environment, and negative emotions related to the same. This will result in most cases to a reduced efficacy in one's profession. The burnout syndrome is linked only with the occupational context, and does not apply to other stress related experiences that occur during a specific period or during lifetime.

A less technical definition is briefly described in Kaplan \& Sadock's Comprehensive Textbook of psychiatry: "syndrome of physical or emotional exhaustion considered to be a stress reaction to unrelenting performance and emotional demands stemming from one's occupation; symptoms include impaired work performance, fatigue, insomnia, increased susceptibility to physical illness, and reliance on alcohol (or other substances) with a tendency to escalation into physiological dependency or possible suicide".

Burnout is not recognized as a distinct psychiatric disorder, hence is not considered from a complete nosologic point of view. Yet there are pathological elements. Depending on the solutions found for treating burnout, if not treated it can lead to various comorbidities, most common being moderate/severe depression, generalized anxiety, and addiction. And a full psychiatric disorder can ensue, which means the affliction of the sympathetic and the parasympathetic nervous system, plus the pathology o the axis comprising the hypothalamus, the hypophysis and the adrenal glands.

Simply put the interpretation of stress goes into overdrive, the stress hormones (cortisol, adrenaline, noradrenaline) are produced in excess, and the autonomous nervous system cannot regulate itself to a normal standpoint.

All the definitions and literature appear to point out a common culprit: stress. The modern human has almost the same nervous or digestive system, as the humans that lived 2 million years ago, which developed modern traits, as Homo Erectus or Homo Ergaster. As a comparison, they 
were hunter-gatherers, ate lean game meat, picked fresh fruits and vegetables, and drank milk only as newborns. After the Agricultural Revolution, humans began eating meat from domestic animals, ate cereals, and drank milk for a longer period in life. As the inherited digestive system was the same, gluten or lactose are not processed entirely, as humans lack the proper enzymes for it; hence many cases of gluten or lactose intolerance exist in the present. In the same manner, the brain areas that interpret stress remained almost the same. These brain areas function automatically, so the stress is biologically and individually processed by each individual brain. There are complex genetic and epigenetic interactions as to why some people develop pathology after prolonged stress and others do not; as two soldiers that go through the same traumatic event, one develops PTSD, the other remains biologically unaffected. Humans from two million years ago lived in a stressful environment, they had to be vigilant and alert to many dangers; this means that genes in the brain areas that control stress interpretation were selected over generations to contribute to survival in an extremely challenging world. As the present world has changed drastically and as we have almost the same nervous system as two million years ago, our brain areas tend to go into overdrive when automatically interpreting stress.

As the Latin etymology suggests, stringere "to draw tight", stress takes a toll, dysregulates the normal functions of the neuroendocrine system. If not managed first by psychosocial education, it can develop various psychiatric comorbidities.

Stress can come from various causes, but the concept of burnout correlates stress with work. Most people can relate to the feeling of being stressed because of work. Some jobs appear to be more stressful than others, to mention doctors, police, firefighters, etc., which seems to involve proximity to survival or loss of life. As the modern world becomes more and more technologized, burnout can be seen in media, tech, corporations, etc. It is not hard to imagine how at a biological level the brain automatically interprets survival as a need to reach deadlines, make more money, live up, or surpass the expectations from work. These qualities have become almost similar to surviving in a hostile environment, like two million years ago.

No matter the work environment or the person's job, the brain can interpret in a stressful manner; this takes a toll on the neuroendocrine system, which produces the symptomatology described above; this prolonged condition can lead to comorbidities, not only psychiatric but also somatic (digestive and cardiovascular diseases).

As it is not a psychiatric disorder per se, managing burnout syndrome is at first recommended via psychosocial education : Stress related to work can be managed with different coping mechanisms, that can be developed rationally by one's self or with the help of a therapist: keep track of stressful factors and identify the stressful situation at the job; develop some healthy and meaningful responses, like managing your sleep pattern, exercises or mediation; create boundaries between the time spent at work and that at home; try to ask a supervisor or the person in charge for support during work (American Psychological Association, 2015).

Cognitive-behavioural therapy has statistically relevant results of being effective in managing burnout, especially by changing one's coping mechanisms and using techniques of managing stress by altering one's reflexive response to it.

Psychiatric medication is recommended in the presence of comorbidities, like depression, anxiety and substance abuse. Various antidepressants have positive effects, especially in a first episode of the disorder, as SSRIs (escitalopram, sertraline) or in more episodes non-responsive to previous medication SNRIs (duloxetine, venlafaxine), adjuvants as mirtazapine, all are statistically proven to work better than placebo. The important matter in initiating treatment with an antidepressant is that it has to be taken a minimum of 9-12 months, even if the symptomatology 
disappears a short time after the initiation of treatment (this prevents relapse and is also related to the time that it takes for an antidepressant to stabilize the DNA of the malfunctioning neurons). Other various treatments that are seen in practice more and more in these days, mostly benzodiazepines, low dosage antipsychotics or tricyclic antidepressants, are not recommended, as each pose a great risk for side effects due to their multi-receptor profile (the medication binds on too many receptor sites on the neuron).

This can be considered a complementary perspective to the biological one, not dissociative.

The biological explanation does not affirm that the automatic interpretation of stress is a cause for burnout, as in the same working conditions some suffer from burnout and some do not. The biological explanation underlies the innate mechanism of automatic interpretation of stress. The coping mechanism of an employee contributes psychosocially to the biological explanation and can be considered a small part of the cause. In the end, the working environment can take a toll on a person on a biopsychosocial level: it can trigger the activation of one's irrational coping mechanism and in the end, affects the holistic biology of an individual.

\section{Burn out from a non-medical prospective: across the industries}

In the book Time, Talent Energy by M. Mankins and E. Garton, a new perspective to burnout is given. There are different types of burn outs, for instance employee burnout and organisation burn out. Both of them happen due to common sense culprits: detailed procedures, halo effect and no time to break from one task to another and restore to a certain personal and professional comfort. As much as a systemic logic of action and coordination is important, from both organisation and employee perspective, serious consideration has to be given to weak time management and certain procedures revisited.

One big question about burn out is whether it is a problem of the employee or a problem of a company. Experts take sides and camp arguing that both approaches are valid, however, the practice is to treat burn out as a matter of organisational behaviour, since burnout syndrome is not conceived as being a medical disorder by the World Health Organisation. A recent research conducted on 16.000 employees observed that $69 \%$ of participants have had burn out, women being more affected than men. (Zur, 2020) The numbers are slightly more encouraging in Australia, where only about $43 \%$ of the employees ever experienced burn out according to Exercise Experience Scale, the Perceived Stress Scale and the Maslach Burnout Inventory. The number is far much positive compared to the rest of the world, yet, it is far from encouraging when considering the Australian job market. Surprisingly, in the Netherlands research shows that in a sample of 40.000 employees only $14.6 \%$ employees experienced burn out in 2016 . In comparison in Portugal only $15 \%$ of employees are likely to experience burn out, however an alarming $73 \%$ were at moderate risk (Eurofound, 2018). Worldwide, the trend is that employees in the public sector suffer more from burn out than the reported cases from the private sector, by $20 \%$ (Bretland, R. and Thorsteinsson, E. 2015; Eckhaus, 2021).

According to the World Health Organisation, the yearly cost of burnout that burdens the global economy has been estimated to be 255 billion pounds. Other sources and calculations, present a rather similar number, 300 billion USD, varying between $\$ 125$ billion to $\$ 190$ billion. These large amounts led WHO to predict that burnout will be a pandemic phenomenon in the next decade. (WHO, 2019)

Regardless of the industry, common causes of burnout are considered lack of leadership, 'bad colleagues', routine, heavy workloads, bad time management and inconsistency of work- tasks that get interrupted and had to be continued later, after other tasks are performed. A Microsoft 
study discovered that it takes employees 15 minutes to re-focus on their original task after they have to answer an e-mail. (Garton, 2017) It is considered that such work interruptions lead to low productivity, frustrations, lack of fulfilment, lack of time feeling, stress, depersonalisation and eventually burn out (Jais and Asokumar, 2020).

Personal accomplishment and satisfaction at the workplace is a way to tackle burn out because it gives a sense of emotional stability, control of life, optimism and a different type of mindset. Accordingly, burn out is not a matter of the job itself, though that may contribute, but rather of the reaction of the individual to the work colleagues, tasks and how the 'system' is perceived or sometimes even imagined.

Other studies found personal accomplishments at work is not the key factor that drives burn out, but supports professional efficacy which in turn has a negative correlation to burn out. Lopez-Nunes et al. (2020) argue for a positive correlation in between the level of workload and the level of burn out. Yet, it is unsure how the personal resources of the individual (optimism, hope, etc) and its characteristic of psychological capital help him in the way. Luthans et al. (2006) considers that "an individual's positive psychological state of development and is characterized by: (a) having confidence (self-efficacy) to take on and put in the necessary effort to succeed at challenging tasks; (b) making a positive attribution (optimism) about succeeding now and in the future; (c) persevering towards goals and, when necessary, redirecting paths to goals (hope) in order to succeed; and (d) when beset by problems and adversity, sustaining and bouncing back and even beyond (resiliency) to attain success"

Burnout is mostly discussed in conjunction with the medical practice, rather than personal matters. But in fact, it can manifest at any level of the industry, where a working person interprets stress in overdrive. Next, non-financial reporting disclosures will be considered, to understand the state of play both in academic and professional literature.

\section{Academic perspectives: Human resources accounting}

Human resources accounting (HRA) had at least five stages of development, starting from the 1960s and generally mirrored aspects that economic development has been based on: leadership, goodwill integration, behaviour organisation, etc. The popularity of HRA dropped in the late seventies only to be rediscovered recently as intangible assets and proper stakeholder disclosures contribute to value creation. Social and employee-related matters generally relate to gender equality, human rights, social dialogue, anti-corruption and bribery, environmental and community protection.

Sürdü et al. (2020) analysed 54 human resource disclosures in corporate annual reports related to employee health and safety, employment of minorities, gender, disabled employee, training, salaries, employee morale and benefits. Her research concentrated on whether such disclosure exists and what determined companies to actually report these non-financial matters. This study concludes that human resource disclosures are connected with return on assets (ROA), return on equity (ROE) and other financial matters. Similarly, Dominguez (2011) established a correlation between "the effect of human resources on company's value and concern the effect of organizations on employees' wellbeing." Furthermore, Arvidsson (2011) narrowed the scope and looked at specific measurements for human resources like employee satisfaction, employer attractiveness, employee turnover and sick days leaves, among other data, while Stone (1998), quoted in Sürdü's article concludes that 'productive use of people in achieving the organization's strategic business objectives and the satisfaction of individual employee needs'. 
The opposite is also valid, for instance employee mistreatment at Uber puts value at risk and affects sustainability and produces chances in the business model as there is no clear-cut line in between financial and non-financial aspects of reporting (Hoinaru, et al. 2019). Commenters argue that Uber's brand reputation was suffering after a 90 second call where 400 people were fired. The protests at its headquarters done by independent contractors affected financially the company, some customers left possibly inspired by \#DeleteUber movement and other sexist allegation, threats of lawsuits followed by negative media headlines made the company drop down in value with $15 \%$ accordingly to CNBC (2017), Washington Post (2019) One former Uber chief human resources officer acknowledged employee burnout in the company, commenting: "Many employees are very tired from working very, very hard as the company grew," and also "Resources were tight and the growth was such that we could never hire sufficiently, quickly enough, in order to keep up with the growth." (O’Donovan, Anand, 2017).

In general, non-financial reporting complements or rather supplements financial understanding and it is assumed that intellectual capital fulfils the gap in between Market Value (MV) and Booked Value (BV). Bukh, Larsen and Mouritsen (2001) severely criticise the argument, however due to increase subjectivity in human capital valuation it is difficult to construct and capture, and also criticise, the exact value of human resources employed at work (Steen, Welch \& McCormack, 2011). Data reported is dry and only indirectly connected like sick leave days, employee turnover, which are rather effects of burnout. Of course, aspects of corruption, or gender inequality can motivate highly motivated people. Interesting enough is that if the organisational practices affected the performance of one individual, that individual is going to affect the functioning of the organisation. Therefore, it is important for a company to describe, the little they do, what is the internal policy on human resource treatment and how they resolve certain issues. As a strategy to avoid losses, some firms prefer voluntary disclosures and mass media reports to show their contribution to society, sustainability, improving of social, cultural, and environment in the companies that they financially perform. In this sense, there is a multitude of frameworks that companies can report under like Integrated Reporting <IR> or Global Reporting Initiative (GRI), Sustainability reporting index (SRI), covering different corporate deporting needs or broader perspectives.

\section{Accountability and practice}

Our research is based on Annual reports from corporations covering different industries to check on their reporting. The companies were randomly chosen in the order they were provided by Google search engine. Adidas in one such example, where their Annual report reads that employees and customers are immensely valuable to the company from a human perspective, yet financial aspects cannot be possibly ignored. The statement is rather contradictory, as on one hand they put employees in the centre of attention, however, meanwhile they are a consumer-centric organization, which may suggest a profit before people approach (Adidas, 2019).

When investigating further, trying to make sense of the company governance and internal policy, it looks that Adidas, considering their business products, encourages sports inside the firm, as a modern practice of mental health at the workplace. Former employee reviews available on Glassdoor.com support this point of view, criticism being rather concentrated on lack of leadership and big employee turnover. which our research identified as variables of burn-out, however we could not establish clear correlations (Glassdoor, 2021).

A lot of effort seems to be placed on internal reporting on measuring employee satisfaction, including a survey named People Pulse as well as a description of the scale they use and 
methodology. The main question of the survey consists of a scale of satisfaction and likeliness to recommend the firm as a good employer. The answers and reports based on the surveys seem to be generally positive, or stable, however, the 67\% response rate in 2018 is rather worrying. Even though this number is not an accurate indicator of People Pulse and the Net Promoter Score, it offers certain hints on employees' time management, eagerness in replying, or interest in company internal surveys. Again, there is no direct connection with burnout, as we lack access to full data and context (Adidas, 2019).

Another company, Allianz's report provides evidence that stakeholder involvement is connected to materiality, the ESG being somewhat an outside matter. Within the ESG the most detailed part of the report are 'Social matters' where general societal matters are mentioned, like major challenges to society, as well as Allianz's value as an employer. In a similar fashion to Adidas, consumer issues and sales management is surprisingly present at the expense of the other category. In terms of employee matters the United Nations Universal Declaration of Human Rights is mentioned as a major act, as well as the binding Vendor Code of Conduct composed on labour standards and human rights, consisting of faire practices, fight against modern slavery and human trafficking (Allianz, 2017).

In terms of keeping employees, Allianz has a series of metrics among which are the Allianz Engagement Survey (AES), Inclusive Meritocracy Index and the Work Well index (WWi). All of them and others are linked to the Group's Board of Management. All the data is backed up also by VOICE, an initiative which started in 2016, where employees can raise their concerns, engage more and work at different levels, promote ideas and also by Simplithon which is another platform where employees can feedback dialogues, express concerns and simplify work.

The most recent Allianz People Fact Book (2019) shows that this company has 147,268 employees, out of which $51 \%$ are women, and the average age is about 40 years old, with mixed backgrounds and ethnicities. Generally, the report shows positive data and attitudes towards the company, like an average 66\% Work Well Index (WWi) and only 8.1 sick days per year on average per capita, including an award of 'Dream workplace' in Indonesia and top 25 in Spain. Other massively positive data showed a high score of $72 \%$ Employee Engagement Index (EEI) with 7.8\% turnover rate in Germany (Allianz, 2019).

Back in 2019, without any previous knowledge on Covid 19, the year 2020 was considered to be 'Mental Health Year'. Allianz acknowledged that mental illness is a leading problem worldwide causing sick leave or mental absence and that this is a challenge to be addressed. In this sense Allainz was envisioning itself as a leader and a potential provider of best practices and a community carrier via inclusion and diversity. The self-image was that :'our employees are highly motivated to help shape a culture that values the contributions of all employees and together with our leaders, who are engaged in leading the necessary inclusion dialog, we will continue to progress toward a work environment where all employees feel they belong.' (Allianz, 2019).

\section{Discussions and conclusion}

Aggregated data is rather worrying especially for Western Europe and USA, where $85 \%$ of employees are not engaged in the workplace and $81 \%$ of employees are considering leaving their jobs as two Gallup studies reveal. This means that employees generally perceive their workplace as a negative environment. Among causes, one in three employees blame routine, getting bored or 'toxic colleagues and bosses'. In this sense, quitting personnel does not leave behind companies but rather people, as one CEO noted (Smarp, 2021). 
Research by Deloitte shows that the vast amount of employees, regardless if C-level or not, think that clear goals have to be present for a positive corporate culture. This motivates people, provides transparency, makes performance measurable and generally avoids negative feelings and resentments in a team as they know the value system and how they rank against it, even if they may be a team of competing colleagues, goals shape the environment in a positive manner (Deloitte, 2012).

As far as now it could be noticed that firms report positive data in order to shape a particular image, attract shareholders and create stakeholder value. Aspects of gender balance, equal payment, equal opportunities and even positive discrimination, community involvement and good care of environment as well as other debatable subject, even though hardly objectively measured are part of disclosures. Data is manipulated in such a way to create confidence, improve market efficiency or at least avoid losses. Internal metrics created after bespoken methodologies help building up brand image and capital as they cast the company in a positive light. External reporting, like media reports and interviews with employees can also help attract talent and keep situations under control.

Even though metrics on employee satisfaction, employee morale and benefits data, employee engagement surveys exist, the indexes look rather decentralised and are not harmonised in reporting practices. Eurofound, when looking at burn out in the working place, they consider the following scales: Maslach Burnout Inventory (MBI) (and its various associated versions) and the Copenhagen Burnout Inventory (CBI), the Shirom-Melamed Burnout Measure (SMBM), while acknowledging other tools like 'Burnout assessment tool', led by KU Leuven and other more specific ones used at national level (Eurofound, 2018).

Generally, many EU Member States are prepared to recognise burnout as an actual disease (since 2010), however, there is no clear EU harmonisation plan, as some countries classify it as occupational disease, limiting its applicability to certain industries only. There are also problems with timely recognition, when this neuropsychiatric disorder is already installed. In extreme cases, death can be an effect of burn-out, when nothing can be done any longer.

The EU should agree more on characteristics of burnout, whether hypertension can be an indication of burn-out (Zinchenko et. al, 2016) and also on common classification criteria within ICD-11. Some countries reference sub category Z, especially 'Z73.0 Burnout' as a distinct subcategory is described as a 'state of vital exhaustion' while others prefer code F, specifically F43.8A - 'fatigue syndrome, adaptation disorders and response to severe stress' (Eurofound, 2018).

World wide data is far from encouraging and rather worrying, as in certain countries $69 \%$ of the workers experienced burn out, $75 \%$ are at moderated risk of experiencing it and $81 \%$ of the employees consider changing their job mainly because they do not feel engaged at their workplace or are getting bored. Other data from countries like Portugal are more encouraging, however, the discrepancy in data may show the different definitions used, or data adaptations. The World Health Organization (WHO) is considering burn out as the next pandemic that could happen.

A place to start in addressing burnout is to revisit human resources accounting and the nonfinancial standards, what CSR and ESG actually means. It also has to be recognised that working with people is hard due to personality types, different needs, reactions, etc. Accountancy Europe, from a more financial perspective, argued that 'Without human capital, there is no capital" (Accountancy Europe, 2021). The tendency to cast a positive image on company practices and report on value is a natural practice responding to market efficiency hypothesis. Work life balance started also to be redesigned, as a non-zero sum game, especially as business models and leadership get challenged and changed. In a similar fashion to Haslam et.al (2016) who suggested stress 
testing in financialized reporting entities within IFRS, considering the economic judgement applied, impact of regulation, also human factors should be accounted as financial stability forbearance benchmark materiality in the public interest (ICAEW, 2018).

\section{References}

Accountancy Europe. (2021). Without human capital, there is no capital. Available at https://www.accountancyeurope.eu/professional-matters/without-human-capital-there-isno-capital/.

Adidas (2019). Annual Report 2019. Available at https://report.adidas-group.com/2019/en/groupmanagement-report-our-company/people-and-culture/people-strategy.html.

Allianz (2019). People Fact book.

Allianz (2017). Annual report 2017.

American Psychosocial Association (2015). Coping with Stress at Work. Available at https://www.apa.org/monitor/2015/12/pc.

Arvidsson, S. (2011). Disclosure of non-financial information in the annual report. J. Intellect. Cap., 12, 277-300.

Bretland, R,. and Thorsteinsson, E. (2015). Reducing workplace burnout: the relative benefits of cardiovascular and resistance exercise. Peer J, 3, e891. Available at https://www.ncbi.nlm. nih.gov/pmc/articles/PMC4393815/.

Bukh, P., Larsen, J., and Mouritsen, J. (2001). Intellectual Capital and the 'Capable Firm': Narrating, Visualising and Numbering for Managing Knowledge. Accounting Organizations and Society, 26(7-8), 735-762.

CNBC (2017). Scandals may have knocked \$10 billion off Uber's value, a report says. Available at https://www.cnbc.com/2017/04/25/uber-stock-price-drops-amid-sexism-investigationgreyballing-and-apple-run-in--the-information.html.

Deloitte (2012). Core beliefs and culture. Available at https://www2.deloitte.com/content/dam/ Deloitte/global/Documents/About-Deloitte/gx-core-beliefs-and-culture.pdf.

Dominguez, A.A. (2011). The impact of human resource disclosure on corporate image. J. Hum. Resour. Costing Account, 8, 4-20.

Eckhaus, E. (2021). "The Fourth Dimension of Happiness and Work Satisfaction", Management \& Marketing. Challenges for the Knowledge Society, 16(2), 118-133, DOI: 10.2478/ mmcks-2021-0008.

EFRAG (2021). Non-Financial reporting. Available at https://www.efrag.org/Activities/ 2010051123028442/Non-financial-reporting-standards.

Eurofound (2018). Burnout in the workplace: A review of data and policy responses in the EU, Publications Office of the European Union, Luxembourg.

Garton, E. (2017). Employee Burnout Is a Problem with the Company, Not the Person. Harvard Business Review, April 62017.

Glassdoor.com (2021). Adidas Employee Review. Available at https://www.glassdoor.com/ Reviews/Employee-Review-adidas-RVW4620451.htm.

Haslam, C., Tsitsianis, N., Hoinaru, R., Andersson, T., \& Katechos, G. (2016). "Stress Testing International Financial Reporting Standards (IFRS): Accounting for Stability and the Public Good in a Financialized World," Accounting, Economics, and Law: A Convivium, De Gruyter, vol. 6(2), 93-118, July.

Hoinaru, R., Negreanu, F., De Luca, A. (eds.) (2019). Driving down greenhouse gases: A roadmap for the Paris Agreement, Brussels: Printing Unit of the European Parliament, $66 \mathrm{p}$. 
ICAEW. (2018) IFRS 9: Six variables to watch in a stress test. Available at https://www.icaew .com/technical/financial-services/banking-sector/ifrs-9-six-variables-to-watch-in-a-stresstest.

ICD-11. International Classification of Diseases, Available at https://icd.who.int/en.

Jais, J., and Asokumar, A. (2019). "Psychological Process, Social and Environmental Influence on Retirement Planning: Malaysian Energy Industry Perspective", Management \& Marketing. Challenges for the Knowledge Society, 15(2), 134-153. DOI: 10.2478/ mmcks-2020-0009.

Lopez-Nunes et al. (2020). Psychological Capital, Workload, and Burnout: What's New? The Impact of Personal Accomplishment to Promote Sustainable Working Conditions. Sustainability 2020, 12(19), 8124.

Luthans, F. et al. (2006). Psychological capital development: toward a micro-intervention. Journal of Organizational Behaviour, 27(3), 387.

Mankins, M., and Garton, E. (2017). Time, Talent Energy. Boston: Harvard Business Review Press.

O'Donovan, C and Pryza, A.(2017). How Uber's Hard-Charging Corporate Culture Left Employees Drained. Available at https://www.buzzfeednews.com/article/caroline odonovan/how-ubers-hard-charging-corporate-culture-left-employees.

Roman, A., Mocanu, M., and Hoinaru, R. (2019). Disclosure Style and Its Determinants in Integrated Reports Sustainability, 11(7), 1960.

Sadock, B. et. al. (2017). Kaplan \& Sadock's Comprehensive Textbook of psychiatry, Apphen: Wolters Kluwer.

Smarp (2021). 8 Employee Engagement Statistics You Need to Know in 2021. Available at https://blog.smarp.com/employee-engagement-8-statistics-you-need-to-know.

Steen, A., Welch, D., McCormack, D. (2011). Conflicting conceptualization of human resource accounting. Journal of Human Resource Costing and Accounting. 15 (4) pp. 299-312.

Stone, R.J. (1998). Human Resource Management; John Wiley and Sons: Brisbane, Australia.

Sürdü et al. (2020). Human Resource Disclosures in Corporate Annual Reports of Insurance Companies: A Case of Developing Country. Sustainability, 12(8), 3452.

Washington Post (2019). Internal data shows Uber's reputation hasn't changed much since \#DeleteUber. Available at https://www.washingtonpost.com/technology/2019/08/29/evenafter-ubers-ipo-long-shadow-deleteuber-still-looms/.

World Health Organisation (2019). Burn-out an "occupational phenomenon": International Classification of Diseases. Available at https://www.who.int/news/item/28-05-2019-burnout-an-occupational-phenomenon-international-classification-of-diseases.

World Economic Forum (2016). It's costing the global economy £255 billion, so what can we do to stop workplace burnout? Available at https://www.weforum.org/agenda/2016/10/work place-burnout-can-you-do-anything-about-it.

Zinchenko Yu.P., Pervichko E.I., Ostroumova O.D. (2016). Burnout syndrome in patients with workplace hypertension. Rational Pharmacotherapy in Cardiology., 12(6), 675-680.

Zur, S. (2020). HRE's Number of the Day: employee burnout, Available at Are employees feeling burnout?|HRExecutive.com.

DOI: $10.2478 /$ picbe-2021-0065, pp. 695-704, ISSN 2558-9652 |

Proceedings of the $15^{\text {th }}$ International Conference on Business Excellence 2021 